\title{
Abuse of Prescription and Over-the-Counter Medications
}

\author{
James E. Lessenger, MD, and Steven D. Feinberg, MD, MPH
}

The nonmedical use of prescription or over-the-counter (OTC) medications implies that the user is using them for reasons other than those indicated in the prescribing literature or on the box label. The abuse of these medications is a national issue.

Intentional drug abuse of prescribed and OTC medicines has climbed steadily. Data from the 2005 National Survey on Drug Use and Health demonstrated that 6.4 million (2.6\%) people aged 12 or older had used prescription drugs for nonmedical reasons during the past month. Of these, 4.7 million used pain relievers, 1.8 million used tranquilizers, and 1.1 million used stimulants. The nonmedical use of prescription drugs in the past month among young adults aged 18 to 25 increased from $5.4 \%$ in 2002 to $6.3 \%$ in 2005 , primarily because of an increase in the abusive use of pain relievers.

Physicians need to watch for prescription and OTC medication abuse. Treatment strategies include (1) inquiring about prescription, OTC, and herbal drug use at the initial examination (even though many individuals are drug-abuse savy, some are naïve and do not realize that OTC medications can be problematic); (2) inquiring about drug use during office visits; (3) providing disposal containers that patients can use to dispose of their unused or unneeded prescription or OTC medications; (4) treating pain aggressively and appropriately; (5) practicing careful record keeping of prescription refills and controls over prescription blanks; (6) referring patients who are addicted to medications to 12-step programs such as Alcoholic Anonymous, Narcotics Anonymous, and Pills Anonymous; and (7) considering detoxification. (J Am Board Fam Med 2008;21:45-54.)

The nonmedical use of a prescription or over-thecounter (OTC) medication implies that the user is using it for reasons other than those indicated in the prescribing literature or on the box label. ${ }^{1}$ The abuse of these medications is a national issue. Prescription medications are those pharmaceuticals dispensed by a pharmacist on the presentation of a prescription written by a physician, dentist, or other health care provider who is legally authorized to write prescriptions. OTC medications are pharmaceuticals that do not require a prescription and are sold on the shelves of markets, stores, and pharmacies. $^{2}$

This article was externally peer reviewed.

Submitted 11 March 2007; revised 28 July 2007; accepted 7 August 2007.

From private practice, Benicia, California (JEL), and the Department of Orthopaedic Surgery-Physical and Rehabilitative Medicine, Stanford University School of Medicine, California (SDF).

Funding: none.

Conflict of interest: none declared.

Corresponding author: James E. Lessenger, MD, FAAFP, FACOEM, 750 West K Street, Benicia, CA 94510 (E-mail: agbook@lessenger.net).

\section{Scope of the Problem}

Intentional drug abuse of prescribed and OTC medicines has climbed steadily over the years. Data from the 2005 National Survey on Drug Use and Health demonstrated that 6.4 million $(2.6 \%)$ people aged 12 or older used prescription psychotherapeutic drugs for nonmedical reasons during the previous month. Of these, 4.7 million used pain relievers, 1.8 million used tranquilizers, and 1.1 million used stimulants (including 512,000 using methamphetamines). Nonmedical use of prescription drugs in the previous month among young adults aged 18 to 25 increased from $5.4 \%$ in 2002 to $6.3 \%$ in 2005 . This was primarily because of an increase in the use of pain relievers, which was $4.1 \%$ in 2002 and $4.7 \%$ in 2003, 2004, and 2005 . $^{3}$

In 2005, among people aged 12 or older who used pain relievers for nonmedical reasons in the previous 12 months, $59.8 \%$ reported that it was obtained free from a friend or relative. Another $16.8 \%$ reported they obtained the drug from one or more doctors. Only $4.3 \%$ purchased the pain relievers from a drug dealer or other stranger, and 
Table 1. 2002 Emergency Department Admissions from Use of Prescription and Over-the-Counter Medications

\begin{tabular}{lccc}
\hline Substance & $\%$ & Age at First Use & Source of Feferral \\
\hline Opioids & 55 & 26 & Self \\
Stimulants & 28 & 20 & Criminal justice system \\
Tranquilizers, muscle relaxers & 10 & 24 & Self \\
Sedatives & 6 & 23 & Self \\
OTC medications & 1 & 20 & Self \\
\hline
\end{tabular}

Data from the National Survey on Drug Use and Health. ${ }^{5}$

OTC, over the counter.

$0.8 \%$ reported buying the drug on the Internet. In 2005 the specific illicit drugs that had the highest levels of dependence or abuse in the previous year were marijuana (4.1 million), cocaine (1.5 million), and pain relievers (1.5 million). Nonmedical use of pain relievers (2.2 million) and marijuana (2.1 million) accounted for the largest number of first-time abuse among people aged 12 or older. ${ }^{3}$

In a recent New Mexico study of deaths from unintentional drug poisoning, $0.9 \%$ were from OTC medications. ${ }^{4}$ A 2004 national survey demonstrated that suicide-prone patients with a diagnosis of substance abuse who possess prescription medications are more likely to overdose on OTC medications. $^{5}$

A study of Tulare County, California, Drug Court clients found that $8.5 \%$ admitted to abusing prescription drugs and $16.2 \%$ admitted to abusing OTC medications, mostly ephedrine and other stimulants. None of the clients admitted to prescription drugs or OTC medications as their drugof-choice (DOC), although some admitted addiction to Vicodin after the study was completed. ${ }^{6}$ This study suggests that some drug addicts may only resort to prescriptive or OTC medications when their illegal drugs are not available.

In emergency departments in the United States, prescription and OTC drugs were the primary substances of abuse for $4 \%$ of the 1.9 million patients admitted for drug treatment in 2002. Prescription medications were primarily opioids, stimulants, tranquilizers, and sedatives. OTC drugs included aspirin, cough syrup, diphenhydramine and other antihistamines, sleep aids, and other legally obtained medications. ${ }^{7}$ In 2002, 55\% of the total drug-related emergency department admissions were for prescription narcotics. Most of the people seen in the emergency departments were white and female and had never had a previous emergency department visit because of illicit drugs. Compari- son with 1992 data demonstrated an increase in opiate and OTC use, with a relative decrease of sedative and tranquilizer use. The use of stimulants remained the same $e^{7,8}\left(\right.$ Table $\left.1^{5}\right)$.

\section{Trends in Use}

People use potentially addicting prescription or OTC medications in the following manners:

- For legitimate, prescribed medical treatment; for example, methamphetamines for narcolepsy and opiates for severe trauma.

- As an additional drug to use when the DOC is unavailable on the streets.

- As a booster for a more intense high.

- As an alternative addictive drug when their DOC has been eliminated from use by drug testing.

- As an alternative addictive drug prescribed by physicians; for example, amphetamines in diet clinics. These prescriptions may be issued either naively by the physician or for profit. ${ }^{9,10}$

Data from the Drug Abuse Warning Network demonstrate the following about people who abuse prescription or OTC medications:

- They tend to be white.

- They tend to be younger (when stimulants are the DOC).

- They tend to use opiates.

- They tend to be women; women tend to use tranquilizers and sedatives.

- They tend to mix their medications with alcohol.

- They tend to use prescription and OTC medications in conjunction with alcohol as a vehicle for suicide.

- They obtain the prescription medications by prescription from their physicians or dentists, as gifts from friends, or purchase them on the black 
market. OTC medications are, of course, purchased at stores. $^{7,8,11,12}$

Many of the medications in this paper have legitimate medical uses for people with a variety of illnesses and injuries. They may even be used in high doses for selected medical problems. The question arises as to whether the medication is being prescribed by the physician and used by the client appropriately or if it is being inappropriately prescribed or used. This problem is most common in the use of opioids and stimulants. ${ }^{13}$

When a legal medication is the addict's primary DOC, it was either prescribed by a physician or purchased on the streets. There are 3 people involved in the abuse: (1) the physician, who either knowingly or naively prescribes pharmaceuticals to a person who is faking pain; (2) the person who fakes or exaggerates an illness to obtain a prescription, which is then filled in a pharmacy and may be sold at locations where he or she can obtain high prices; and (3) the addict who purchases the medications for his own use. ${ }^{10,13}$

Physicians who prescribe or dispense medications that can be abused are at risk for becoming part of the problem. Some physicians are part of the illegal network of drug sales, but others fall into the trap of trying to help people as best they can. Recent campaigns to treat pain as a vital sign along with blood pressure, pulse, respiratory rate, and temperature make it necessary for professionals to treat pain aggressively and appropriately. The Federal and state governments' campaign against the illicit use of prescription opiates, on the other hand, has made it difficult at times for patients to obtain relief for the pain of cancer or a debilitating disease. Under-treatment of pain has also become a problem among prescribing physicians, resulting from fears of investigation by regulatory agencies. Physicians have found themselves fearful of government sanctions if they prescribe these medications. Paradoxically, some patients refuse to take opiates and other medications for pain control at the end of their lives for fear of becoming addicted. ${ }^{13,14}$

Professionals who prescribe or work around controlled drugs also are at risk of abusing readily available medications and becoming addicted. Part of the problem is that not only do the professionals divert medications for their own use, but, in some cases, they rob patients of necessary medications. ${ }^{9}$

\section{Dependence on Medication and Pseudo-addiction}

There are clear differences between the physical dependence on medication, active addiction, addiction in remission, and pseudo-addiction. The dependence on medication may be therapeutic regardless of the class to which it belongs. Physical dependence of a therapeutic drug may occur, resulting in withdrawal symptoms if the medication is suddenly stopped. This is a physiologic response to the chronic use of a medication, just as stopping a blood pressure medicine suddenly can cause hypertension, heart attack, or stroke. Drug-seeking behavior, actions to obtain drugs either by a prescription or otherwise, may in some people reflect not addiction but rather difficulty in obtaining appropriate medications because they are labeled as addicts. Some people with a history of addiction to illicit drugs may also have a chronic pain syndrome that would benefit from appropriate opiate pain medication. A person recovering from drug addiction may need a stimulant for narcolepsy or a tranquilizer for anxiety. If these problems are undertreated because of physician fear, a syndrome of pseudo-addiction may occur, in which the person engages in drug-seeking behavior simply to obtain a therapeutic and effective dosage level of a medication. $^{14}$

Patients in drug-addiction recovery may be even more vigilant than the physician. They are acutely aware of the consequences of relapse and do not want to experience the problems of addiction again. For that reason, some people in recovery may forgo opioid medications even in the face of severe trauma. ${ }^{14}$

\section{Disposal of Prescription and OTC Medications}

A recurring problem facing patients in drug addiction recovery is the disposal of prescription and OTC medications they have on hand. Especially early in their program, patients may have hundreds of prescription and OTC tablets as well as herbal preparations and supplements. They may be using these as part of their abuse pattern or keeping them in case their addictive cravings overwhelm them. ${ }^{15}$

Disposal of these remedies becomes problematic because the patients cannot throw them in the trash, which could be searched by law enforcement authorities. A similar situation exists if they try to give it to friends. In many states, pharmacies cannot legally take back the medications and other pharmacies may refuse because of liability concerns. In addition, there are many environmental concerns 
Table 2. Commonly Used Prescription Drugs with Potential for Abuse

\begin{tabular}{lll}
\hline Category & \multicolumn{1}{c}{ Drugs } & \multicolumn{1}{c}{ Examples } \\
\hline Sedatives & Barbiturates & Amytal, Nebutal \\
& Flunitrazepam & Rohypnol \\
Dissociative anesthetics & Ketamine & Ketalar SV \\
Opioids and morphine & Codeine & Tylenol with codeine \\
\multicolumn{1}{c}{ derivates } & Fentanyl & Duragesic \\
& Morphine & Duramorph \\
& Opium & Laudanum \\
& Others & Oxycontin \\
Stimulants & Amphetamines & Dexedrine \\
& Cocaine & Cocaine hydrochloride \\
& Methamphetamine & Desoxyn \\
Anabolic steroids & Methylphenidate & Ritalin \\
Tranquilizers and & Benzodiazepines & Anadrol \\
muscle relaxers & Carisoprodol & Soma Halcion \\
\hline
\end{tabular}

Data from the National Institute on Drug Abuse. ${ }^{17}$

about the disposal of medications and contaminated syringes. A possible solution might be to provide locked, hazardous waste collection containers at the physician's offices where a patient can dispose of used syringes and medications. ${ }^{6}$

Although this article focuses on abuse, there are other nonmedical uses of prescription medications. These include bartering, especially in jails and prisons; use as a mechanism of suicide; use as a mechanism of homicide; and accidental ingestion. ${ }^{16}$

\section{Abused Prescription Drugs}

Commonly abused prescription drugs are summarized in Table 2. Detection of these pharmaceuticals is difficult because the Federal Department of Transportation drug test panel, or a standard forensic drug test panel, may not pick up some of these substances, including oxycodone. Detoxification and withdrawal from any of the medications may be problematic and may require inpatient treatment and appropriate pharmacological support (Table 2). ${ }^{17}$

The Internet is a major source of prescription drugs that are used for nonmedical uses. A 2006 survey documented that $89 \%$ of sites selling controlled prescription drugs have no prescription requirements, a figure that is down from $94 \%$ in 2004 . Of the $11 \%$ of sites that required a prescription, $70 \%$ only required a prescription be faxed, allowing a customer to easily forge prescriptions or fax the same prescription to several Internet pharmacies. There has also been a trend toward online consultation in lieu of a prescription. In 2006, 99 Web sites offered such a service. ${ }^{18}$

\section{Sedatives}

Barbiturates are typically used as a sedative and anticonvulsant, but they have an equal role as the means to decrease the likelihood of seizures and other symptoms in alcohol, heroin, and other types of drug withdrawal. This class of medications is easily abused as a hypnotic and overdose is common, resulting in death through respiratory depression. They are addictive but tolerance can occur; a withdrawal syndrome exists, consisting of agitation, headaches, psychomotor retardation, confusion, and possible seizures. Addicts may seek out barbiturates as a sleep aid and as a method of selfdetoxification if they know that a Department of Transportation drug test is nearing. ${ }^{19}$

\section{Opioids and Morphine Derivatives}

Considerable controversy exists about the use of opioids for the treatment of chronic pain not originating from cancer and the resulting increase in medications available for diversion to illicit use. Under-treatment of pain has also become a problem among physicians because of fears of investigation by regulatory agencies. One response to under-treatment has been the appearance of drugseeking behavior among people with legitimate non-cancer pain. ${ }^{20}$ Myriad state and Federal laws and polices provide physicians with a confusing picture of when and to whom these medications can be prescribed.

A recent survey of physicians regarding drug abuse showed that doctors perceive the 4 mechanisms of diversion to be (1) doctor shopping to find a cooperative professional; (2) obtaining controlled substances from multiple doctors; (3) patient deception or manipulation of doctors; and (4) forged or altered prescriptions. ${ }^{16} \mathrm{~A}$ fifth source, not well studied, consists of doctors and dentists who prescribe controlled drugs for money or who divert them for their own use. Reports from England document that most opioids that are used by addicts for nonmedical indications are prescribed by a small number of physicians. ${ }^{21}$ 


\section{Stimulants}

Of particular concern are stimulant medications used to treat attention deficit hyperactivity disorder. In 2004, there were 7873 emergency department visits by people who were found to be suffering from poisoning because of the nonmedical use of amphetamine-dextroamphetamine or methylphenidate. Of visits to the emergency department for attention deficit hyperactivity disorder medication problems, $48 \%$ were for nonmedical use of the medications, $34 \%$ were adverse reactions associated with medical use, $10 \%$ were accidental ingestion, and $8 \%$ were suicide attempts. The rates were higher for the 12- to 17-year-old age group than for patients aged 18 or older. Over two thirds $(68 \%)$ of the visits involved nonmedical use of these 2 drugs and another substance, such as alcohol, an illicit drug, or a pharmaceutical. ${ }^{8}$

\section{Tranquilizers and Muscle Relaxers}

Benzodiazepines are commonly diverted for nonmedical uses. They are typically prescribed as sleep aids or as anti-anxiety medications. They are also useful in detoxification from alcohol or other substances and are useful in the treatment of convulsive disorders. Overdose can cause respiratory depression, especially when used with other sedative medications or alcohol. ${ }^{22}$

There is a syndrome of paradoxical disinhibition that results in increased excitement, irritability, aggression, hostility, and impulsivity. In rare cases, these conditions can lead to attacks of rage or violence or other antisocial behaviors. Tolerance can develop with the use of these medications. ${ }^{22}$ High benzodiazepine doses are used by addicts to enhance the euphoria effects of opioids; boost methadone or heroin fixes; temper cocaine highs; augment the effects of alcohol; or ease the effects of withdrawal from heroin, methadone, and other drugs. $^{22}$

Muscle relaxants can also be addicting. Carisoprodol, a centrally acting muscle relaxant sold under the name of Soma, is an example. Its active metabolite is meprobamate, a class IV substance and a highly addictive and potent sedative-hypnotic. Ingestion can cause addiction and a mild sense of euphoria. Higher doses cause euphoria and impaired hand-eye coordination and balance. Tolerance exists and there is a withdrawal syndrome of anxiety, tremor, muscle twitching, insomnia, auditory and visual hallucinations, and bizarre behavior. ${ }^{23}$

\section{Pharmaceuticals for Erectile Dysfunction}

Sildenafil (Viagra; Pfizer, Inc., New York, NY) has become the sentinel erectile dysfunction medication in the drug-using culture; an underground network of faked prescriptions, foreign imports, and Internet purchases exists. Both homosexual and heterosexual men and women are documented to have demonstrated drug-seeking behavior with this substance. ${ }^{24}$ In a survey of sexually active males aged 18 to 25 years, $13 \%$ reported erectile dysfunction and $6 \%$ used medications, but rarely under medical supervision and often mixed with recreational drugs. ${ }^{25}$ Among British illicit drug users, Sildenafil use among night clubbers, a sentinel population of illicit drug users, was first reported in 1999. Use by both men and women was reported, with elevated prevalence levels among both gay men and women. ${ }^{26}$

Among gay men and women, Sildenafil along with cocaine, crystal methamphetamines, amyl nitrate poppers, Ecstasy, gamma-hydroxybuterate, and ketamine has become a "club drug." 27 Methamphetamine and Sildenafil use are linked to unprotected receptive and insertive anal sex, respectively, in a sample of gay men. ${ }^{28}$ Sildenafil use appears to have become a stable fixture of the sexual culture of gay men and is associated with a general behavioral risk patter for transmission of HIV and other sexually transmitted diseases. ${ }^{29}$ The concomitant use of Viagra, testosterone, and antidepressants among HIV-seropositive gay and bisexual men has been associated with unintended negative effects because of the additive risk of side effects. ${ }^{30}$

Recent anecdotal evidence suggest that Sildenafil abuse is becoming increasingly popular among Ecstasy users to attempt to negate the erectile dysfunction side-effects of the drug or to enhance the drug experience through the concomitant use of erectile dysfunction drugs. ${ }^{31}$

\section{Abused OTC Drugs}

OTC drugs are easily purchased, are difficult to detect on routine drug testing, and can be used as an alternative DOC when the addicted person's primary drug had been removed. ${ }^{32}$ The literature is sparse about OTC medications and herbal remedies. Herbal remedies are especially problematic because they can be sold at swap meets and other unregulated venues; they are not subject to the scrutiny of the Food and Drug Administration; 
Table 3. Abused Over-the-Counter Medications (Representative List)

\begin{tabular}{|c|c|c|c|c|}
\hline Class & Medication & Medical (Legal) Use & Nonmedical Use & $\begin{array}{l}\text { Physical Findings of } \\
\text { Nonmedical Use }\end{array}$ \\
\hline Dietary supplements & $\begin{array}{l}\text { Supplement with } \\
\text { piperazine }\end{array}$ & Anorexia & Hallucinations & Acute psychosis \\
\hline \multirow[t]{5}{*}{ Dissociative substances } & Dextromethorphan & Cough suppressant & Dissociative effect & Psychiatric effects \\
\hline & Coricidin & Decongestant & Euphoria & Euphoria psychosis \\
\hline & Chlorpheniramine & Decongestant & Euphoria & Euphoria psychosis \\
\hline & Dimenhydrinate & Antiemetic & Euphoria, hallucinations & $\begin{array}{l}\text { Extreme euphoria, } \\
\text { hallucinations }\end{array}$ \\
\hline & Diphenhydramine & Sedation & Euphoria "high" & $\begin{array}{l}\text { Tachycardia, euphoria, } \\
\text { hallucinations, psychosis }\end{array}$ \\
\hline Stomach preparations & $\begin{array}{l}\text { Calcium-bromide } \\
\text { combinations }\end{array}$ & $\begin{array}{l}\text { Antacid stomach } \\
\text { medication }\end{array}$ & Euphoria, hallucinations & Neuropsychiatric symptoms \\
\hline \multirow[t]{9}{*}{ Stimulants } & Nicotine gum & Smoking cessation & "High" & Agitation \\
\hline & Phenylpropanolamine & Decongestant & $\begin{array}{l}\text { "High" physical } \\
\text { performance } \\
\text { enhancement }\end{array}$ & Agitation, rapid heartbeat \\
\hline & Ephedrine & Anti-asthma & $\begin{array}{l}\text { Prolonged erection and } \\
\text { sexual performance }\end{array}$ & Priapism \\
\hline & Pseudoephedrine & Decongestant & $\begin{array}{l}\text { Prolonged erection and } \\
\text { sexual performance }\end{array}$ & Priapism \\
\hline & Methylephedrine & Decongestant & $\begin{array}{l}\text { Prolonged erection and } \\
\text { sexual performance }\end{array}$ & Priapism \\
\hline & Caffeine & Awareness & Performance enhancement & Agitation, rapid heartbeat \\
\hline & Ephedra & Stimulant & "High" & $\begin{array}{l}\text { Agitation, tachycardia, } \\
\text { flushing }\end{array}$ \\
\hline & Cyclizine & Antihistamine & Euphoria & Euphoria \\
\hline & Epinephrine & Bronchodilator & Euphoria & $\begin{array}{l}\text { Headache, nausea, chest } \\
\text { pains }\end{array}$ \\
\hline Laxatives & $\begin{array}{l}\text { Oral and rectal } \\
\text { laxatives }\end{array}$ & Anticonstipation & Psychological dependence & GI disturbances \\
\hline Sedatives & Diphenhydramine & Sedation & Sedation & Somnolence, coma \\
\hline Steroids & $\begin{array}{l}\text { Androstenedione } \\
\text { (herbal sources) }\end{array}$ & $\begin{array}{l}\text { Hormone } \\
\text { replacement }\end{array}$ & Exercise enhancement & $\begin{array}{l}\text { Acne, glandular failure, } \\
\text { hyperaggressive behavior }\end{array}$ \\
\hline \multirow[t]{2}{*}{ Herbal } & Antidepressant & Antidepressant & $\begin{array}{l}\text { Adverse psychiatric } \\
\text { reactions }\end{array}$ & Psychosis \\
\hline & Detox cocktail & Detox from drugs & Serotonin syndrome & Psychosis \\
\hline
\end{tabular}

they may be imported from other countries, especially Mexico and China, that do not have strict controls on their contents; they may include heavy metals such as lead; the there are few systematic studies of efficacy or safety. ${ }^{32}$ A representative list of abused OTC drugs is found in Table 3. Particularly dangerous drugs or combinations of drugs are discussed individually below (Table 3).

\section{OTC Steroids in Exercise Gymnasiums}

In a study of 511 men entering 5 exercise gymnasiums it was found that $18 \%$ reported use of androstededione or other anabolic steroids to increase muscle mass; $25 \%$ used ephedrine as a stimulant. Among the same group, 5\% reported anabolic ste- roid use within the last 3 years. Among women the rates were $3 \%, 13 \%$, and $0 \%$, respectively. ${ }^{33}$

\section{Dextromethorphan}

Dextromethorphan hydrobromide (DXM, or "robo"), a constituent of more than 125 OTC cough and cold remedies, is the most popular cough medication in the United States and is widely used in other parts of the world. The most common source of DXM is "extra-strength" cough syrup, which contains $3 \mathrm{mg}$ of the drug per $1 \mathrm{ml}$ of syrup. The recommended dose for treating coughs is $1 / 6$ to $1 / 3$ ounce of medication containing $15 \mathrm{mg}$ to $30 \mathrm{mg}$ of DXM. At higher doses it produces a dissociative effect similar to phencyclidine and ketamine. $^{34}$ 
Cough syrups or capsules also contain additional ingredients such as acetaminophen, chlorpheniramine maleate, guaifenesin, and pseudoephedrine. Toxicity with overdose is additive to that of DXM alone. An unknown number of adolescents in the United States and Europe intoxicate themselves with acute megadoses of dextromethorphan, defined as 5 to 10 times the dose recommended for control of annoying nonproductive coughs. Although a moderate overdose of pure DXM hydrobromide is free of serious adverse effects, approximately $5 \%$ of people of European ethnicity lack the ability to metabolize the drug normally, leading to rapid, acute toxic levels. Variable quantities of pure DXM powder in multiples of $1 \mathrm{~g}$ are available from the Internet. Recipe-like extraction procedures are available online, allowing for simple and inexpensive home manufacture of concentrated DXM powder from Coricidin HBP Cough \& Cold Tablets (Schering-Plough HealthCare Products, Inc., Kenilworth, NJ) (street name "triple C"). Acute megadoses of the drug have profound psychological and physiologic effects similar to those of phencyclidine. Megadoses of DXM used to self-intoxicate can produce a false-positive screening test for phencyclidine in a urine specimen. ${ }^{35}$

DXM can cause psychosis, dependence, and physical withdrawal. It has specific serotonergic and sigma-1 opioidergic properties. Dextrorphan, the active metabolite of DXM, has similar properties; however, it is a weaker sigma opioid receptor agonist and a stronger $\mathrm{N}$-methyl-D-aspartic acid receptor antagonist. DXM and its metabolite, dextrorphan, display specific biological features of addiction, including tolerance, and are capable of inducing specific psychiatric sequelae. There are more profound and potentially life-threatening effects at even higher doses. Dextrorphan has pharmacodynamic properties and its intoxication effects produce dissociation, a state that abusers seek. Withdrawal is manifested by a profound depression. ${ }^{36}$ Chronic addiction has been described in the literature. $^{37}$

\section{Coricidin Intoxication}

Coricidin HBP is a popular OTC antihistamine and decongestant that is safe and effective when used as directed on the product label. It is also sold as Coricidin D, Coricidin D (long acting), and Coricidin D (cold, flu, and sinus). These medications contain a combination of dextromethorphan hydrobromide, chlorpheniramine maleate, phenylpropanolamine hydrochloride, and acetaminophen. The Texas Poison Network reported 78 cases of Coricidin intoxication from 1998 to 1999. Of these 78 cases, $63 \%$ of the patients were men and $38 \%$ were women. The mean age was 14.67 years, with $77 \%$ being between 13 and 17 years old. Eighteen different symptoms were reported: tachycardia (50\%); somnolence (24.4\%); mydriasis and hypertension $(16.7 \%)$; agitation $(12.8 \%)$; disorientation (10.3\%); slurred speech (9\%); ataxia (6.4\%); vomiting $(5.1 \%)$; dry mouth and hallucinations $(3.9 \%)$; tremor $(2.6 \%)$; and headache, dizziness, syncope, seizure, chest pain, and nystagmus (1.3\% each). ${ }^{38}$

\section{Rapture}

A 20-year-old man developed a brief psychotic episode associated with per secutory delusional beliefs and auditory and visual hallucinations, leading him to commit arson. The episodes occurred 12 hours after he took large doses of an OTC dietary supplement containing piperazine, a stimulant known on the streets as "rapture." The patient also used small doses of cannabis and nitrous oxide and had no prior psychiatric history. He reportedly completely recovered. ${ }^{39}$

\section{Dimenhydrinate}

The OTC anti-emetic dimenhydrinate (Gravol or Dramamine) is a compound of diphenhydramine and 8-chlorotheophylline. Drug users abuse it for the acute effects of euphoric sensations and hallucinations, whereas psychiatric patients abuse it because of its anti-anxiety effects. ${ }^{40}$ Patients suffering from schizophrenia may be at risk because of its anticholinergic effects. One report suggests that clozapine reduces cravings for dimenhydrinate. ${ }^{40}$

Dimenhydrinate is an $\mathrm{H} 1$ histamine receptor antagonist but it interacts either directly or indirectly with other neurotransmitter systems, including acetylcholine, serotonin, norepinephrine, dopamine, opioids, or adenosine. Animal behavioral studies looking at self-administration, conditioned for place preference, drug discrimination, and modulation of operant responding, show that antihistamines have abuse potential. Further support comes from reports of acute and chronic abuse of dimenhydrinate by humans. ${ }^{40}$ 


\section{Diphenhydramine}

The antihistaminic drug diphenhydramine is mainly used as a sedative, hypnotic, and antiemetic. In many countries it is available OTC under the name Benadryl. It is very common and generally regarded as a harmless drug. The recreational goal and the intoxication syndrome affect 2 separate populations differently. People with a nonaddictive genetic constitution use it as a long-term hypnotic to aid with sleeping. Those with a genetic predisposition to addiction use it for the subjective high of a stimulant. ${ }^{41}$

The intoxication symptoms are also inconsistent. Some people present with somnolence, sedation, and retardation. In people with a genetic predisposition to addiction, there are tachycardia, anticholinergic syndrome, agitation, hallucinations, confusion, tremor, convulsions, delirium, and coma. A toxic psychosis is possible. Diphenhydramine can be used orally or intravenously. Medical personnel are at risk for addiction because diphenhydramine is commonly on stock in hospitals and clinics to treat allergic reactions. Tolerance does exist with this OTC medication, and withdrawal results in sedation and memory impairment. ${ }^{42,43}$

\section{Hydroxycut}

Because herbal products are not subject to the same rigorous Food and Drug Administration regulations that are required for prescription and OTC products, consumers unknowingly risk adverse effects when taking these products. A 22-year-old man was hospitalized after unexplained seizure-like activity and unresponsiveness. A urine toxicology screen was negative for salicylates, acetaminophen, alcohol, and drugs-of-abuse. Medical history was insignificant with the exception of recent (within 2 weeks) ingestion of Hydroxycut, a dietary supplement purported to enhance energy, build muscle, and burn fat. The agent contains ephedra alkaloids and caffeine, both of which are central nervous system stimulants. The seizure was attributed to their consumption. Because of a significant number of reported adverse events, the Food and Drug Administration proposed regulations for dietary supplements containing ephedra alkaloids and requested an independent review of case reports linked to these products. ${ }^{44}$

\section{Cyclizine}

Abuse of cyclizine hydrochloride, a nonprescription medication, was noted to occur frequently in Utah. Cyclizine is an OTC antihistamine. A retrospective review of the Utah Poison Control Center records of patients younger than 18 years of age who intentionally ingested cyclizine and demonstrated abuse accounted for $89 \%$ of cyclizine toxic ingestions. Hallucinations (70\%) and confusion and disorientation (40\%) were the most notable symptoms. Tachycardia (52\%) and systolic hypertension $(69 \%)$ were frequently present in patients who presented to a hospital. No serious complications occurred. The researchers concluded that abuse of OTC medications by adolescents may be more appealing than illicit drug use for numerous reasons, and may be more common than appreciated. $^{46}$

\section{oTC Analgesics}

Using high levels of OTC analgesics, including aspirin and acetaminophen, over long periods of time have been associated with dysphoric mood states. Phenacetin, which was taken off the market in the 1970s, had intoxicating effects and produced a dissociative state. ${ }^{34}$

\section{Intravenous Epinephrine}

A case that demonstrates the lengths that people will take to convert OTC medications to drugs of abuse concerns a 19-year-old man who intravenously injected $1.1 \mathrm{mg}$ of epinephrine (adrenalin) that was removed from an OTC bronchodilator inhaler usually used for asthma. The man had a history of intravenous cocaine and amphetamine abuse. Within seconds, he developed headache, nausea, numbness of the hands and feet, chest pain, and palpitations. The electrocardiograph demonstrated ischemic changes. ${ }^{46}$

\section{OTC Hypnotics (Sleep Aids)}

Used in excess amounts, OTC sleep aids (Sominex, Nytol, and Sleep Eze) can cause hallucinations, delirium, and confusion. When use is stopped, recovery is rapid and there is no withdrawal syndrome. ${ }^{41}$

\section{Strategies for Physicians}

Physicians must be on the alert for prescription and OTC medication abuse. Strategies that can be em- 
ployed include (1) inquiring about prescription, OTC, and herbal drug use at the initial examination (although many individuals are drug-abuse savvy, some are naïve and don't realize that OTC medications can be problematic); (2) inquiring about illegal drug use during office visits; (3) providing disposal containers that patients can use to dispose of their unused or unneeded prescription or OTC medications; (4) treating pain aggressively and appropriately; (5) practicing careful record keeping of prescription refills and controls over prescription blanks; (6) referring patients who are addicted to medications to 12 -step programs such as Alcoholic Anonymous, Narcotics Anonymous, and Pills Anonymous; and (7) considering detoxification, either inpatient or outpatient.

\section{References}

1. DuPont RL. Prescription stimulant abuse. Psychiatr Ann 2005;35:93-7.

2. Collins GB, McAllister MS. Combating abuse and diversion of prescription opiate medications. Psychiatr Ann 2006;36:410-6.

3. Substance Abuse and Mental Health Services Administration. Results from the 2005 National Survey on Drug Use and Health: national findings. Rockville (MD): Office of Applied Studies, NSDUH Series H-30, DHHS Publication no. 2006;SMA 064194.

4. Center for Disease Control and Prevention. Unintentional deaths from drug poisoning by urbanization of area: New Mexico, 1994-2003. MJWR 2005; 54:870-3.

5. National Survey on Drug Use and Health. Nonmedical use of prescription pain relievers. Washington, DC: Office of Applied Studies, Substance Abuse and Mental Health Services Administration; 2004.

6. Lessenger JE, Lessenger LH, Lessenger EW. An outcome analysis of Drug Court in Tulare County, California. Visalia (CA): Tulare County Superior Court; 2000.

7. National Survey on Drug Use and Health. Characteristics of primary prescription and OTC treatment admissions: 2002. Washington, DC: Office of Applied Studies, Substance Abuse and Mental Health Services Administration; 2004.

8. Drug Abuse Warning Network. Emergency department visits involving non-medical use of selected pharmaceuticals. Washington, DC: Office of Applied Studies, Substance Abuse and Mental Health Services Administration; 2006.

9. Miller WR, Baca C, Compton WM, et al. Addressing substance abuse in health care settings. Alcohol Clin Exp Res 2006;30:292-302.

10. Goodman FDC, Glassman P. Evaluating potentially aberrant outpatient prescriptions for extended-release oxycodone. Am J Health Syst Pharm 2005;62: 2604-8.

11. National Household Survey on Drug Abuse. Nonmedical use of prescription-type drugs among youths and young adults. Washington, DC: Office of Applied Studies, Substance Abuse and Mental Health Services Administration; 2003.

12. Drug Abuse Warning Network. Emergency department visits involving ADHD stimulant medications. Washington, DC: Office of Applied Studies, Substance Abuse and Mental Health Services Administration; 2006.

13. Miller NS. Physicians and the controlled substance laws for opiate prescription medications. Psychiatr Ann 2006;36:422-9.

14. Weaver M, Schnoll S. Abuse liability in opioid therapy for pain treatment in patients with an addiction history. Clin J Pain 2002;18:S61-9.

15. London M. Prevention of substance abuse. Curr Opin Psychiatry 2001;14:207-11.

16. Gilson AM, Ryan KM, Joranson DE, Dahl JL. A reassessment of trends in the medical use and abuse of opioid analgesics and implications for diversion control: 1997-2002. J Pain Symptom Manage 2004; 28:176-88.

17. National Institute on Drug Abuse. Prescription drug abuse chart. Washington, DC: National Institute on Drug Abuse; 2006.

18. The National Center on Addiction and Substance Abuse at Columbia University. You've got drugs: prescription drug pushers on the internet: 2006 update. New York: The National Center on Addiction and Substance Abuse at Columbia University; 2006.

19. Carter LP, Richards BD, Mintzer MZ, Griffiths RR. Relative abuse liability of GHB in humans: a comparison of psychomotor, subjective, and cognitive effects of supratherapeutic doses of triazolam, pentobarbital, and GHB. Neuropsychopharmacology 2006;31:2537-51.

20. Trescott AM, Boswell MV, Atluri SL, et al. Opioid guidelines in the management of chronic non-cancer pain. Pain Physician 2006;9:1-40.

21. Bewley T, Ghodse AH. Unacceptable face of private practice: prescription of controlled drugs to addicts. BMJ 1983;286:1876-7.

22. Longo L, Johnson B. Addiction: part I. Benzodiazepines: side effects, abuse risk and alternatives. Am Fam Physician 2000;61:2121-8.

23. Reeves RR, Carter OS, Pinkofsky HB, Struve FA, Bennett DM. Carisoprodol (Soma): abuse potential and physician unawareness. J Addict Dis 1999;18: 51-6.

24. Fisher DG, Malow R, Rosenberg R, Reynolds GL, Farrell N, Jaffe A. Recreational Viagra use and sexual risk among drug abusing men. Am J Infect Dis 2006; 2:107-14.

25. Musacchio NS, Hartrich M, Garofalo E. Erectile 
dysfunction and Viagra use: what's up with collegeage males? J Adolesc Health 2006;39:452-4.

26. McCambridge J, Mitcheson L, Hunt N, Winstock A. The rise of Viagra among British illicit drugs uses: 5-year survey data. Drug Alcohol Rev 2006;25:111-3.

27. Fernandez MI, Perrino T, Collazo JB, et al. Surging new territory: club-drug use and risky sex among Hispanic men who have sex with men recruited on the Internet. J Urban Health 2005;82(1 Suppl 1): i79-88. Epub 2005 Feb 28.

28. Mansergh G, Shouse RL, Marks G, et al. Methamphetamine and sildenafil (Viagra) use are linked to unprotected receptive and insertive anal sex, respectively, in a sample of men who have sex with men. Sex Transm Infect 2006;82:131-4.

29. Paul JP, Pollack L, Osmond D, Catania JA. Viagra (sildenafil) use in a population-based sample of U.S. men who have sex with men. Sex Transm Dis 2005; 32:531-3.

30. Purcell Dw, Wolitski RJ, Hoff CC, Parsons JT, Woods WJ, Halkitis PN. Predictors of the use of Viagra, testosterone, and antidepressants among HIV-seropositive gay and bisexual men. AIDS 2005; 19(suppl 1):S57-66.

31. Copeland J, Dillon P, Gascoigne M. Ecstasy and the concomitant use of pharmaceuticals. Addict Behav 2006;31:367-70.

32. Abbot FV, Fraser MI. Use and abuse of over-thecounter analgesic agents. J Psychiatry Neurosci 1998;23:13-34.

33. Kanayama G, Gruber AJ, Pope HG, Borowieckii JJ, Hudson JI. Over-the-counter drug use in gymnasiums: an under-recognized substance abuse problem? Psychother Psychosom 2001;70:137-40.

34. National Institute on Drug Abuse. Hallucinogens and dissociative drugs. Washington, DC: National Institute on Drug Abuse; 2006.
35. Schwartz RH. Adolescent abuse of dextromethorphan. Clin Pediatr (Phila) 2005;44:565-8.

36. Miller SC. Dextromethorphan psychosis, dependence and physical withdrawal. Addict Biol 2005;10: 325-7.

37. Desai S, Aldea D, Daneels E, Soliman M, Braksmajer AS, Kopes-Kerr CP. Chronic addiction to dextromethorphan cough syrup: a case report. J Am Board Fam Med 2006;19:320-3.

38. Baker SD, Borys DJ. A possible trend suggesting increased abuse from Coricidin exposures reported to the Texas Poison Network: comprising 1998 to 1999. Vet Hum Toxicol 2002;44:169-71.

39. Austin H, Monasterio E. Acute psychosis following ingestion of "Rapture." Australas Psychiatry 2004; 12:406-8.

40. Halpert AG, Olmstead MC, Beninger RJ. Mechanisms and abuse liability of the anti-histamine dimenhydrinate. Neurosci Biobehav Rev 2002;26:61-7.

41. Griffiths RR, Johnson MW. Relative abuse liability of hypnotic drugs: a conceptual framework and algorithm for differentiating among compounds. J Clin Psychiatry 2005;66:31-41.

42. Pragst F, Herre S, Bakdash A. Poisonings with diphenhydramine: a survey of 68 clinical and 55 death cases. Forensic Sci Int 2006;161:189-97.

43. Nigro SA. Toxic psychosis due to diphenhydramine hydrochloride. JAMA 1968;203:301-2.

44. Kockler DR, McCarthy MW, Lawson CL. Seizure activity and unresponsiveness after Hydrocut ingestion. Pharmacotherapy 2001;21:647-51.

45. Bassett KE, Schunk JE, Crouch BI. Cyclizine abuse by teenagers in Utah. Am J Emerg Med 1996;14: 472-4.

46. Hall AH, Kulig KW, Rumack BH. Intravenous epinephrine abuse. Am J Emerg Med 1987;5:64-5. 